\title{
ARTIGOS
}

\section{O LEGADO SOCIOLÓGICO DE PIERRE BOURDIEU: DUAS DIMENSÕES E UMA NOTA PESSOAL ${ }^{1}$}

\author{
Loïq J. D. Wacquant \\ University of California, Berkeley \\ Centre de sociologie européene du Collège de France
}

\begin{abstract}
RESUMO
O presente artigo compõe-se de três partes, retraçando e discutindo, em cada uma delas, a vida e a obra sociológica de Pierre Bourdieu, falecido em janeiro de 2002. A primeira parte apresenta a carreira do pensador francês, procurando relacionar cada etapa de sua vida com o desenvolvimento de seu pensamento, desde os estudos primários no interior da França até seu reconhecimento internacional, passando pelo aprendizado de filosofia em Paris e pelas investigações antropológicas na Argélia. A segunda parte consiste em uma discussão, por meio de uma entrevista, da sociologia reflexiva, da "lógica da prática" e de outros conceitos formulados por Bourdieu com o objetivo de estudar a realidade social e incitar à descoberta de novas agendas de pesquisa. A terceira parte tematiza a importância da revista Actes de la recherche en sciences sociales, criada pelo sociólogo e destinada a ultrapassar as várias fronteiras, de nacionalidade ou disciplinares, que cercam e limitam a produção científica.
\end{abstract}

PALAVRAS-CHAVE: Pierre Bourdieu; trajetória intelectual; sociologia reflexiva; lógica da prática; Actes de la recherche en sciences sociales.

\section{INTRODUÇÃO}

Este artigo compõe-se de três diferentes ensaios que, em conjunto, procuram dar uma noção das extraordinárias realizações científicas e da profícua herança intelectual que Pierre Bourdieu legou à comunidade sociológica mundial ${ }^{2}$. A primeira parte, "A vida sociológica de Pierre Bourdieu", foi escrita na primavera de $2002^{3}$ por solicitação da Associação Sociológica Internacional (e será publicada em uma versão diferente, em inglês, em International Sociology; v. WACQUANT, 2002b); ela examina minuciosamente a carreira do autor de $A$ distinção e indica sumariamente seus maiores trabalhos ao longo de sua

1 Tradução de Adriano Nervo Codato e Gustavo Biscaia de Lacerda. Revisão técnica: Adriano Nervo Codato e Renato Monseff Perissinotto.

2 Gostaria de agradecer a Pedro Bodê de Moraes e a Adriano Nervo Codato por tomarem a iniciativa de publicar este ensaio compósito em português.

3 Outono de 2002, no Hemisfério Sul. Notar que todas as estações do ano, do Hemisfério Norte para o Hemisfério Sul, são trocadas (N. T.). trajetória pessoal e intelectual. O segundo artigo foi esboçado na forma de um diálogo com o filósofo Deyan Deyanov na primavera de 2002 para um número especial da revista cultural búlgara KX Magazine, dedicado à "lógica da prática". Ele retrata as descobertas, as contribuições e as aplicações das teorias de Bourdieu para a pesquisa empírica. O terceiro artigo, redigido no início de 1998 para uma enciclopédia do pensamento social francês, dirigida por Lawrence Kritzman (WACQUANT, 1998a), apresenta uma das mais nítidas, embora pouco conhecidas, de suas contribuições para o avanço da ciência social: a criação de Actes de la recherche en sciences sociales, um "grupo de trabalho sociológico" permanente, constituído para derrubar as barreiras do formalismo acadêmico, das disciplinas e do pensamento social pré-construídos, assim como para desenvolver um genuíno internacionalismo científico capaz de restaurar a unidade de uma ciência social autocrítica.

Os maiores pensadores de qualquer época são aqueles que não apenas "fazem descobertas" importantes - essa é a tarefa de qualquer cientista, como, aliás, afirmou Émile Durkheim -, mas 
também são aqueles que causam naqueles à sua volta uma mudança no modo de pensar, indagar e escrever. Pierre Bourdieu pertence a essa categoria, pois ele alterou para sempre a maneira como os estudiosos da sociedade, da cultura e da história em todo mundo, de Tóquio a Tijuana e a Tel Aviv, concebem e exercem seus ofícios. Para ser fiel ao espírito de sua vida sociológica e para continuar seu legado, devemos seguir aplicando suas idéias e testando seus achados a fim de produzir novos objetos de pesquisa.

\section{A VIDA SOCIOLÓGICA DE PIERRE BOUR- DIEU}

Pierre Bourdieu ilustrou brilhantemente e desmentiu enfaticamente suas próprias teorias sociais com uma vida repleta que, por meio de improváveis conversões e mudanças bastante sinuosas, ancorou-se em um fiel compromisso com a ciência, com o institution-building intelectual e com a justiça social. De um ponto de vista sociológico e acadêmico, Bourdieu teve uma trajetória improvável. Como Raymond Aron gentilmente lembrou, Bourdieu foi uma exceção às leis de transmissão do capital cultural que ele mesmo estabeleceu em seus livros iniciais (com Jean-Claude Passeron), Les héritiers: les étudiants et la culture (1964) e La reproduction: élements pour une théorie du système d'enseignement (1970; 1975): neto e filho de agricultores de uma província periférica, ele chegou ao ápice da pirâmide cultural francesa e tornou-se o mais citado cientista social do mundo. Treinado para juntarse à alta casta dos filósofos, a espécie intelectual suprema na França do pós-Segunda Guerra, ele abraçou, ao contrário, a Sociologia, uma disciplina então inferior e moribunda, ajudando a revitalizála e a renová-la, e cuja influência na esfera pública ele propagou como ninguém.

Bourdieu, além disso, também incorporou muitos de seus ensinamentos e de suas notáveis inovações teóricas em sua própria prática de pesquisa e em sua produção científica. Sua perspectiva de que a ação social é governada por disposições adquiridas pela imersão contínua em jogos sociais encontrou expressão em sua insistência e habilidade para fundir trabalho teórico de alto nível com atividades prosaicas de investigação. Seu brado por uma ciência social reflexiva, capaz de controlar seus próprios vieses, bem como se manter independente de "ritos de instituições" é exemplificado em sua Leçon sur la leçon (1982; 1988b), uma vivisecção de sua aula inaugural no Collège de France, e em Homo academicus (1984), uma análise impiedosa dos determinantes sociais da produção intelectual da universidade francesa - e portanto dele mesmo, como um acadêmico. Sua convicção de que o racionalismo é plenamente compatível com o historicismo e dota a Sociologia de uma indispensável missão social é materializada nos variados, mas convergentes, escritos publicados nos últimos anos, como nos livros Méditations pascaliennes: éléments pour une philosophie négative (1997a; 2001e) e Science de la science et reflexivité (2001c). Seu engajamento pessoal nas lutas sociais contra a globalização neoliberal e na defesa da autonomia intelectual, dos desempregados, dos desabrigados e dos imigrantes ilegais pode ser lido em seus ensaios políticos reunidos em Contre-feux (1 (1998a; 1998e) e 2 (2001b; 2001d)). Seu compromisso com o "corporativismo do universal" é amplamente manifesto em seus incansáveis esforços para disseminar os instrumentos do pensamento crítico e para criar um "intelectual coletivo" capaz de fazer avançar uma Realpolitik transnacional da razão.

\section{II.1. Elementos biográficos}

Pierre Bourdieu nasceu em agosto de $1930 \mathrm{em}$ Béarn, uma região rural do sudoeste da França, encravada no pé dos Pirineus, em uma minúscula vila cuja língua nativa ainda era o occitânico. Seus dias na escola fundamental foram passados entre os filhos de camponeses, de operários e de pequenos comerciantes em outra vila remota conhecida por seu arcaísmo, e que, mais tarde, tornar-se-ia o local de seus primeiros estudos etnológicos - e assunto de seu último livro publicado, por ocasião de seu passamento em 23 de janeiro de 2002, Le bal des célibataires: crise de la société paysanne en Béarn (2002b), no qual diagnostica a crise da sociedade camponesa de sua juventude, promovida pelo deslocamento das estratégias maritais e das relações de gênero. Após se distinguir nos estudos no ensino médio em uma cidade próxima, Pau, onde ganhou fama por ser um ávido jogador de rúgbi e de pelota basca, o jovem Bourdieu recebeu uma bolsa de estudos e foi aconselhado por um de seus professores, aluno da École Normale Supérieure, a inscrever-se no melhor curso preparatório para essa instituição de elite, o khâgne do Liceu Louis-le-Grand de Paris, que reunia os melhores estudantes do país em uma atmosfera de intensa competição e devoção acadêmica. 
Bourdieu logo ingressou na École Normale Supérieure, onde, como seu sucesso exigia, assumiu a rainha das disciplinas, a Filosofia. Mas, em reação à moda da época, dominada pelo existencialismo sartriano que marcava amplamente a educação e a vida intelectual, ele mergulhou no estudo da lógica e da história da ciência graças à influência de Alexandre Koyré, Jules Vuillemin, Eric Weil (cujo famoso seminário sobre a Filosofia do Direito de Hegel ele seguiu), Martial Guéroult (um grande especialista em Leibinz sob cuja orientação ele escreveu um trabalho sobre as Animadversiones), Gaston Bachelard e Georges Canguilhem (que também haviam orientado Michel Foucault alguns anos antes). Após passar na agrégation em Filosofia (juntamente com Jacques Derrida, Louis Marin e Emmanuel Leroy Ladurie), o brilhante recém-graduado elegeu para ensinar Filosofia o Liceu de Moulins, uma pequena cidade na região central da França. Um ano depois, em 1955, foi chamado pela bandeira francesa a Versalhes, mas, sendo inerentemente rebelde à autoridade militar, foi rapidamente enviado, por motivos disciplinares, à Argélia, a fim de servir na missão de "pacificação" da colônia norte-africana.

Essa vivência imediata das dolorosas realidades das guerras travadas pela França contra o nacionalismo argelino mudou o destino intelectual de Bourdieu para sempre: a experiência despertou seu interesse pela sociedade argelina, de um ponto de vista político e científico, e promoveu, na prática, sua conversão da Filosofia para a Ciência Social. Seu primeiro livro, Sociologie de l'Algérie, escrito em 1957 (2001a [1957]) e traduzido nos Estados Unidos em 1962 (The Algeriens, editado pela Beacon Press), era um estudo acadêmico impecável, sintetizando conhecimento histórico, etnológico e sociológico, mas que também incluía a bandeira da nascente Argélia independente. Bourdieu advertiu sobre as contradições da sociedade colonizada e sobre as desilusões do movimento nacionalista (antecipando o atoleiro no qual vários países do Terceiro Mundo encontraram-se presos por décadas após suas independências).

Bourdieu conduziu seus primeiros inquéritos antropológicos nas regiões, marcadas pela guerra, de Kabylia, Collo e Ouarsenis, três baluartes da guerrilha nacionalista. Desde o princípio, ele conjugou a etnografia com estatísticas, a interpretação microscópica com a explanação macroscópica, para mapear o cataclismo social produzido pelo capitalismo colonial e a luta de libertação nacional. Ele procurou ligar as estruturas sociais envolventes às formas culturais, como pode ser visto em seus dois livros, Travail et travailleurs en Algérie (de 1963, sobre a descoberta do trabalho remunerado e a formação do proletariado urbano argelino) e Le déracinement (de 1964, com Abdelmalek Sayad, sobre a destruição da sociedade e da agricultura tradicionais argelinas), e em sua coleção de ensaios etnológicos clássicos Algérie 60 (de 1977, sobre as noções de honra e de tempo entre os kabila, e sobre o "desencantamento do mundo" sob a pressão do trabalho assalariado e da economia de mercado).

Ao lado de sua formação filosófica e de sua personalidade, as circunstâncias peculiares nas quais Bourdieu efetivamente treinou a si mesmo em Antropologia, Sociologia e Estatística, e levaram-no aos estudos de campo que lhe serviram como trampolim empírico para o seu inovador Esquisse d'une théorie de la pratique (1972), explicam sua preocupação característica pela reflexividade: seja para transformar continuamente as ferramentas sociológicas em prática científica, seja para refletir criticamente sobre as condições sociais e as operações concretas de construção do objeto. Essa era uma exigência prática incontornável, às vezes mesmo uma questão de vida ou morte, na Argélia beligerante. A necessidade de controlar as distorções que a postura analítica - que Bourdieu denominaria depois "o ponto de vista escolástico" - introduz na relação entre o observador e o observado, entre a vida social real e as observações que o sociólogo produz dela, é um pilar e um tema centrais de sua carreira, indo desde Le métier de sociologue (juntamente com Jean-Claude Chamboredon e Jean-Claude Passeron - 1990 [1968]; 2000) passando por The Logic of Practice (1990a), e chegando a Méditations pascaliennes (1997a; 2001e) e sua discussão contínua das "três formas da falácia escolástica" que nos conduzem a "tomar as coisas da lógica pela lógica das coisas" na Ciência, na Estética e na Ética.

Gradualmente, o brilhante estudante destinado às honras filosóficas e ao estudo histórico da Epistemologia (seus planos iniciais para depois de dar baixa exército eram ensinar Filosofia e então entrar na Escola Médica de Toulouse, como Canguilhem, que supervisionava sua carreira, havia feito) estava tornando-se um antropólogo. Bourdieu aprendeu um pouco de árabe e de berbere, primeiro no campo e depois nas Écoles des langues orientales, em 
Paris, e assimilou o estruturalismo de Lévi-Strauss; ensinou na Universidade de Algiers e levou adiante um extenso trabalho de campo lá até 1960, quando o golpe pró-colônia em Algiers forçou-o a voar rapidamente a Paris ("liberais" como ele estavam sob ameaça de morte). De volta à França, ele assumiu uma posição como Professor Assistente na Sorbonne e depois na Universidade de Lille, onde, pela primeira vez, leu sistematicamente e ministrou cursos sobre Durkheim, Weber, Marx, Schutz e Saussure, bem como sobre a Antropologia britânica e a Sociologia norte-americana, da qual ele era um entusiasmado consumidor. Simultaneamente, ele continuou a analisar dados de campo coletados durante as freqüentes viagens à Argélia rural e urbana que fez durante seus meses de férias até 1964.

\section{II.2. Da Antropologia à Sociologia}

Foi nessa época que Bourdieu tornou-se Diretor de Estudos da École des Hautes Études en Sciences Sociales e fundou o Centre Europenée de Sociologie, por solicitação de Aron, que recebera um grande auxílio da Fundação Ford. Lá ele treinou e reuniu por mais de três décadas um produtivo grupo de acadêmicos que investigaram as mais variadas questões com foco nas relações entre cultura, poder e desigualdades sociais; com uma constante preocupação em unir a teoria rigorosa à observação sistemática, tanto contra as tendências empiricistas da Sociologia norteamericana, quanto contra a inclinação teorizadora do meio intelectual francês fascinado pelos modelos literários, e com um reconhecimento total da "dupla objetividade" do social, como composto de distribuições de recursos materiais e posições, de um lado, e classificações incorporadas por meio das quais os agentes simbolicamente constroem e subjetivamente experimentam o mundo, por outro.

Assim, Bourdieu passou sem sentir da Antropologia para a Sociologia, uma astúcia que ele abraçou porque isso the parecia mais adequado para compreender as complexidades da realidade social - ao invés de obtê-las a uma distância segura, como a Filosofia e a Antropologia estruturalista faziam. Ele procedeu no sentido de combinar em sua prática de pesquisa o racionalismo de Bachelard e o materialismo de Marx com o interesse neokantiano de Durkheim pelas formas simbólicas, a visão agonística de Weber sobre os Lebensordnungen em competição com as fenomenologias de Husserl e Merleau-Ponty. O resultado foi um quadro teórico original, elaborado por meio de e para a produção de novos objetos de pesquisa, objetivando desvendar a multifacetada dialética das estruturas sociais e mentais no processo de dominação.

Em uma década, Bourdieu estendeu sua análise pioneira da contribuição da educação para a perpetuação da desigualdade social em Les héritiers à análise de outras práticas culturais, com Un art moyen: essai sur les usages sociaux de la photographie (1965) e L'Amour de l'art: les musées d'art européens et leur public (BOURDIEU \& DARBEL, 1966), bem como uma série de inquéritos ligados aos microcosmos da religião, da literatura, da ciência, da filosofia, da lei, da política e da alta costura. Nesses e em outros trabalhos, atingindo o ponto máximo com Les Règles de l'art: genèse et structure du champ littéraire (1992; 1996c), no qual ele desvelou "a estrutura e a gênese do campo artístico" nos tempos de Flaubert (em uma resposta indireta à teoria sartriana da criação em O idiota da família), ele afiou e instalou o arsenal conceitual que arma a ciência da prática e a teoria da violência simbólica que lhe granjeou um lugar no panteão sociológico. Bourdieu cunhou a noção de capital cultural e inseriu-o em uma concepção generalizada de capital como "energia social" congelada e conversível. Ele recuperou e retrabalhou o conceito aristotélico-tomista de habitus para elaborar uma filosofia disposicional da ação como propulsora dos socialmente constituídos e individualmente incorporados "esquemas de percepção e apreciação". Ele forjou a nova ferramenta analítica do campo, designando espaços relativamente autônomos de forças objetivas e lutas padronizadas sobre formas específicas de autoridade, para dar força à estática e reificada noção de estrutura e dotá-la de dinamismo histórico. E ele sociologizou o conceito husserliano de doxa para basear a "atitude natural da vida diária" na coincidência das estruturas sociais e mentais por meio das quais o mundo magicamente aparece como auto-evidente e sua composição é posta além do alcance do debate e da elaboração.

Esse trabalho a um só tempo teórico e empírico culminou nas obras magnas gêmeas de Bourdieu, La distinction: critique sociale du jugement (1979a) e The Logic of Practice (1990a), que o conduziram à cátedra de Sociologia do Collège de France em 1981. No primeiro volume, Bourdieu efetua uma revolução copernicana no estudo das classes e das 
culturas ao abolir a sagrada fronteira entre a alta cultura e o consumo ordinário. Vinculando os mais variados domínios da vida, desde a alimentação e o companheirismo até a estética e a política, ele demonstrou que o julgamento não é um dom inato, mas uma habilidade socialmente aprendida que serve para travar lutas de classes negadas, via batalhas simbólicas da vida diária e posturas adotadas em vários "campos da produção cultural". Ele revelou que o espaço social é organizado por dois princípios de diferenciação entrecruzados o capital econômico e o capital cultural -, cujas distribuições definem as duas oposições que circundam as linhas maiores de clivagem e de conflito nas sociedades avançadas, aquelas entre as classes dominantes e as dominadas (definidas pelo volume de seu capital), e aquelas entre frações rivais da classe dominante (opostas pela composição de seu capital). Essa teoria do espaço social, composição de grupos e competição simbólica foi generalizada em The Logic of Practice, no qual dois modos de dominação, pessoal e estrutural, são diferenciados e seus modos de operar traçados por meio da modelagem do "corpo como um operador analógico" da prática. Daí, então, a categoria de poder simbólico, definida como a habilidade para conservar ou transformar a realidade social pela formação de suas representações, isto é, pela inculcação de instrumentos cognitivos de construção da realidade que escondem ou iluminam suas arbitrariedades inerentes, toma o centro do palco. Decifrar os mecanismos da violência simbólica em seus variados disfarces é o objetivo central de livros tais como Langage et pouvoir symbolique (1984 - no qual Bourdieu procurou tratar da lingüística estrutural e estender sua teoria da prática no sentido de abranger as trocas lingüísticas e discursivas), L'Ontologie politique de Martin Heidegger (1988a; 1989d - uma resolução sociológica da acrimoniosa controvérsia acerca dos aspectos políticos da filosofia de Heidegger e um questionamento radical das reivindicações da Filosofia sobre o estatuto extra-social), $L a$ Noblesse d'Etat: grandes écoles et esprit de corps (1989a - uma exploração das bases sociais da dominação tecnocrática nas sociedades avançadas que prenuncia uma teoria do Estado como "monopolizador do uso legítimo da violência simbólica"), e, last but not least, La Domination masculine (1998a; 1999 - entendido como o paradigma do poder manejado sobre o reconhecimento e o não-reconhecimento).

\section{II.3. O intelectual coletivo}

Embora ele tenha se tornado famoso bastante jovem (em meados dos anos 1960, com Lês héritiers) e tenha usado o manto de maître à penser parisiense uma década após o falecimento de Michel Foucault, Bourdieu evitou persistentemente - na verdade, denunciou - as distrações do estrelato midiático e procurou diligentemente salvaguardar a autonomia intelectual, que considerava uma précondição vital para uma Sociologia rigorosa, bem como para uma política vigorosa. Ao invés de juntar-se aos "society games" pelos quais as "revistas intelectuais" francesas são apropriadamente conhecidas, ele devotou suas energias a construir instituições de produção científica protegidas das dependências gêmeas do comando estatal e das regras do mercado. Suas aventuras editoriais, levadas a cabo com suas assistentes de longa data, Rosine Christin e Marie-Christine Rivière, são emblemáticas dessa postura. Por vinte e cinco anos, Bourdieu dirigiu a série Le sens commun na prestigiosa casa Éditions de Minuit, na qual publicou obras clássicas (de Durkheim, Mauss, Cassirer, Schumpeter e Bakhtin), traduções de importantes autores contemporâneos (entre os quais Bateson, Bernstein, Goffman, Goody e Labov), e pesquisas originais de alguns jovens sociólogos e historiadores franceses. O periódico interdisciplinar por ele fundado em 1975 e conduzido até um estágio avançado de sua doença, Actes de la recherche en science sociales, esforçouse por desnacionalizar a Ciência Social, por derrubar as noções pré-construídas do senso comum ordinário e acadêmico e por acabar com as formas estabelecidas da comunicação acadêmica, misturando análise, dados brutos, documentos de campo e ilustrações pictóricas, sob a máxima "expor e demonstrar". Sua combinação rara de exigência conceitual, reflexividade metodológica e pertinência sócio-política capacitaram-no a agir como porta-voz de uma ciência militante da sociedade, que alcançou um público leitor bem mais amplo que aquele circundado pelos muros da academia (o último número de Actes de la recherche publicado sob a supervisão de Bourdieu esboçou uma arqueologia dos "Votos", poucos meses antes das campanhas para a Presidência e para o legislativo franceses, na primavera de 2002).

Por uma década a partir de 1989, Bourdieu dirigiu Liber, uma "revista européia de resenhas de livros", publicada simultaneamente em nove línguas e países europeus, que ele criou para 
acelerar a circulação internacional e a difusão de trabalhos inovadores em Ciências Sociais, nas Humanidades e na Literatura. Liber também revelou uma face artística de sua personalidade intelectual que encontrou sua melhor expressão em suas colaborações com o artista conceitual Hans Haacke (em um livro conjunto, Libreéchange, 1994), com o dramaturgo Philippe Adrien, e o escultor Daniel Buren - uma tentativa de trabalhar com o cineasta Jean-Luc Godard infelizmente fracassou devido aos estilos conflitantes. Consciente dos múltiplos obstáculos que entravam a disseminação de uma Sociologia que pretende minar todas as formas de imposição simbólica, Bourdieu também publicou diversos volumes de ensaios baseados em conferências e seminários proferidos na França e no exterior Questions de sociologie (1980b; 1981), Choses dites $(1987$; 1990c) e Raisons pratiques: sur la théorie de l'action (1994; 1996d) - nos quais ele fornece aos leitores de diferentes países e disciplinas as ferramentas necessárias à compreensão da substância, das inter-relações e das implicações dos vários liames de sua obra.

A mesma combinação de autonomia científica e engajamento cívico compuseram a política das Raisons d'agir Editions, uma editora híbrida, militante e acadêmica, formada no despertar dos movimentos de massa de dezembro de 1995 contra o plano do governo Juppé de diminuir a abrangência das políticas do Estado de Bem-Estar Social, conforme o "pacto da estabilidade" europeu. Lançada graças ao sucesso de vendas em que consistiu a anatomia das fraquezas do jornalismo feita por Bourdieu, em Sur la télévision (1996a; 1997e), e aproveitando o estrondoso sucesso popular do tomo coletivo La Misère du monde (1993a; $1997 \mathrm{f}$ - uma sócio-análise de mil páginas sobre as formas emergentes do sofrimento social na sociedade contemporânea, que foi adaptado para o vídeo e o teatro), as Raisons d'agir Editions tornaram-se um fenômeno editorial da noite para o dia, com cinco best-sellers em dois anos, ajudando a propagar a crítica de Bourdieu às fontes escondidas e às conseqüências imprevistas da revolução neoliberal, onde quer que fosse. O premiado documentário de Pierre Carle, Sociologia como uma arte marcial (2000), captura muito bem como as teorias sociais de Bourdieu e as tomadas de posição públicas vieram informar o pensamento e a ação de incontáveis militantes e de cidadãos comuns, envolvidos em movimentos sociais explosivos por toda a Europa, estendendo-se dos ecologistas e gays aos advogados dos direitos dos sem-teto, das associações anti-racismo e sindicalistas desarmados pela obsolescência dos veículos tradicionais da militância trabalhista. As sutis mudanças no casamento da Ciência Social com a ação política em mais de quarenta anos foram ricamente documentadas no primeiro livro póstumo de Bourdieu, Interventions politiques 1964-2000 (editado por Frank Poupeau e Thierry Discepolo, 2002).

Os numerosos grupos de ativistas intelectuais que Bourdieu guiou ou incitou na década final do século - entre outros, o International Parliament of Writers, a Association for Rethinking Higher Education and Research (Areser), o International Committee for the Defense of Algerian Intellectuals (Cisia), Raisons d'agir, e os General Estates of the European Social Movement - são muitos das pequenas encarnações do "intelectual coletivo" com que ele sonhou, para ser construído através das divisões disciplinares e das fronteiras nacionais, para trazer as competências simbólicas juntas dos artistas e dos cientistas, para apoiar o debate público e para reconstruir uma agenda progressiva viável e verdadeira em relação aos ideais históricos da esquerda traída pela virada neoliberal dos partidos socialistas e trabalhistas em todos os lugares.

Contra o fatalismo e as profecias superficiais e novidadeiras do pós-modernismo, ele acreditava não apenas na Ciência Social como um empreendimento do conhecimento, como também na capacidade da Sociologia para informar um "utopismo racional", necessário à salvação das instituições da justiça social da nova barbárie do mercado livre e do Estado retraído. Bourdieu concebia uma Ciência Social unificada como um "serviço público" cuja missão é "“desnaturalizar' e 'desfatalizar"” o mundo social e "requerer condutas" por meio da descoberta das causas objetivas e das razões subjetivas que fazem as pessoas fazerem o que fazem, serem o que são, e sentirem da maneira como sentem. E dar-lhes, portanto, instrumentos para comandarem o inconsciente social que governa seus pensamentos e limita suas ações, como ele incansavelmente tentou fazer consigo próprio.

\section{LEVANDO BOURDIEU AO CAMPO}

- Para início de conversa, gostaria de perguntar-lhe como você conheceu Pierre Bourdieu - não falo aqui do seminário em conjunto em Chicago, no inverno de 1987, que o levou a 
escrever a dois Um convite à sociologia reflexiva (BOURDIEU \& WACQUANT, 1992), mas a primeira vez que você encontrou-se frente a frente com ele. Perdoe-me a brincadeira, mas quando foi que a "cumplicidade ontológica" entre a "história personificada" em você e a "história objetivada" nos escritos dele tomaram lugar concretamente?

É uma brincadeira de que eu gosto porque ela captura algo de muito real no processo de compartilhamento do conhecimento e da produção intelectual: as teorias elaboradas por alguém pensando podem tomar vida e envolver as mentes, as atividades e os trabalhos de muitos outros ao redor e depois dele. Nós vemos bem isso com Marx e especialmente com Durkheim e os membros do Année sociologique no período clássico, e estamos testemunhando novamente algo parecido com Bourdieu, que formou não discípulos (a Ciência Social não é uma religião, nem suas figuras inovadoras são líderes de seitas, como alguns gostariam de acreditar), mas, por todo o mundo, colaboradores e colegas no projeto de realização de uma ciência da sociedade crítica e reflexiva.

Eu conheci Pierre Bourdieu por acaso, em novembro de 1980. Na época, eu era um calouro de Economia Industrial na École des hautes études commerciales (HEC), a melhor faculdade de administração da França. Estava desapontado e aborrecido com meus estudos e tateava em busca de alguma coisa intelectualmente estimulante. Um amigo levou-me a uma conferência que Bourdieu faria sobre "Questões políticas" na École Polytechnique, próxima a Paris, por ocasião do lançamento de Le sens pratique (eu lera apenas Os herdeiros (BOURDIEU \& PASSERON, 1964) àquela época, portanto tinha apenas uma vaga noção de quem Bourdieu era e o que queria). Fiquei impressionado e intrigado com aquela fala, mesmo que, sinceramente, não tivesse entendido metade dela! Eu compreendi apenas o suficiente para sentir que alguma coisa nova e importante estava sendo dita e que merecia ser pesquisada. Então, junteime a um grupo de estudantes que cercaram Bourdieu ao final do evento. Nós fomos a um café próximo e iniciamos uma discussão sobre as eleições vindouras - isso foi alguns meses antes da disputa presidencial que levou Mitterrand e o Partido Socialista ao poder em maio de 1981. Então, até às quatro horas da manhã seguinte, Bourdieu procedeu à dissecação da política e da sociedade francesas com uma acuidade cirúrgica, dissecando o sistema social e expondo suas entranhas de uma forma que eu nunca imaginara possível. Eu fui instantaneamente tomado. Pensei: "se é disso que a Sociologia trata, então é isso que eu quero fazer".

Assim, eu comecei a cursar Sociologia na Universidade de Paris, ao mesmo tempo em que fazia minha graduação em Economia, e um ano depois, quando Bourdieu ministrou sua aula inaugural no Collège de France (BOURDIEU, 1982; 1988b), eu fui ouvi-lo e cumprimentá-lo. Ele encorajou-me a assistir a seu curso. Logo estava matando aulas da HEC para ouvir suas conferências no Collège. E desenvolvi o hábito de esperá-lo lá fora para colocar questões e mais questões. Além desse padrão de "perseguição intelectual", cresceu uma troca que evoluiu bastante nos anos seguintes, quando eu fazia pesquisas na Nova Caledônia, que depois resultou em plena colaboração quando nos reencontramos em Chicago, dando origem a nosso livro $U m$ convite à sociologia reflexiva (BOURDIEU \& WACQUANT, 1992).

- Você poderia contar-nos mais sobre a estratégia que vocês seguiram nesse livro, em particular o uso de uma "técnica linear de exposição" para revelar a "maneira recursiva e espiralada" (como você mesmo afirmou) de Bourdieu pensar? Como essa técnica de questionamento influenciou a estratégia de Bourdieu para a formulação de respostas?

Note que a parte central do livro consiste em uma "entrevista" apenas aparente: na realidade, ela foi pensada e escrita, diretamente em inglês, como um texto, e um texto no qual investimos cerca de três anos de trabalho - mas não poderíamos chamá-lo de "um diálogo socrático sobre a teoria da prática" sem nos arriscarmos a ser mal-interpretados... Tiramos do seminário que organizei sobre o pensamento de Bourdieu com outros estudantes de graduação na Universidade de Chicago a forma dialógica, com o objetivo de produzir uma explicação acessível e ao mesmo tempo sistemática de suas teorias, apresentar as várias ligações internas entre suas investigações, responder as dúvidas típicas e rebater as objeções recorrentes. O objetivo era capacitar um leitor não-familiarizado com sua $2 u v r e^{4}$ a ter acesso ao seu núcleo concei-

\footnotetext{
4 “Obra”, em francês no original (N. T.).
} 
tual e temático sem ser desviado, estorvado ou mal-orientado a $c u l s-d e-s a c^{5}$ pelas leituras enviesadas tão comuns ou incompreensões, slogans ou estereótipos sobre esse trabalho (como aquela difundida, porém tola, idéia de que Bourdieu é um criador da "teoria da reprodução").

Na seção central do livro, disfarçada como o "Seminário de Chicago", nós trabalhamos no sentido de reunir questões e respostas passo-a-passo, reescrevendo-as em idas e vindas pelo Atlântico, pelo correio, por fax e por telefone (isso foi antes da era do correio eletrônico e da internet), executando um movimento circular que deixasse visível seus principais núcleos conceituais: reflexividade, habitus, capital, campo, dominação simbólica, doxa, a missão dos intelectuais etc., para empenharmo-nos, em cada caso, em situar Bourdieu dinamicamente em um espaço de posições possíveis, a fim de melhor esclarecer seus métodos e posturas específicas em relação às abordagens rivais e aos seus críticos - por exemplo: sobre a lógica prática, para distinguir claramente sua teoria disposicional da ação tanto da teleologia da teoria da escolha racional quanto do mecanicismo etnocêntrico do utilitarismo: para Bourdieu, a ação orienta-se sem visar conscientemente a um objetivo, e os móveis que a orientam transcendem o estreito interesse material.

O principal desafio era tentar "linearizar" um pensamento que é de fato recursivo e espiralado, sem o desfigurar, para estendê-lo ao longo de vetores que se interceptam mas que são separáveis, ao mesmo tempo respeitando suas articulações internas. Se o modo de argumentar de Bourdieu é como uma teia, com ramificações, se seus conceitos-chave são relacionais (habitus, campo e capital são todos constituídos de "feixes" de laços sociais em diferentes estados - personificados, objetivados, institucionalizados - e funcionam muito mais eficazmente uns em relação aos outros), é porque o universo social é constituído dessa maneira, segundo ele. Então nós procuramos reter a conectividade intrínseca da realidade social e o raciocínio sociológico enquanto desfazíamos os emaranhados de ambos, para habilitar os leitores e os usuários do livro a capturar o cerne da ontologia social, do método e das teorias substantivas de Bourdieu. $\mathrm{O}$ fato de Um convite à

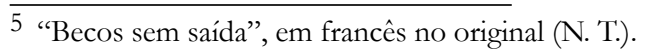

sociologia reflexiva estar agora traduzido em dezessete línguas e considerarem-no o caminho padrão de acesso ao pensamento de Bourdieu sugere que não fomos totalmente mal-sucedidos...

- Recentemente você publicou um livro na França,Corps et âme: carnets ethnographiques d'un apprenti boxeur (WACQUANT,2000; $2002 a$ - a ser lançado em inglês pela University of California Press) que relata uma intensa pesquisa de campo de três anos e meio, levada a cabo em uma academia de ginástica de negros no gueto de Chicago. Você disse-me que nesse livro aplica e desenvolve a teoria do habitus. Você poderia comentar esse experimento de levar Bourdieu a campo e sobre como isso ilumina a problemática da lógica prática?

Corpo e alma é uma explicação antropológica da disputa por supremacia enquanto habilidade corporal no gueto negro norte-americano, baseada na imersão intensiva e na "observação participante", durante a qual tornei-me parte do fenômeno a fim de analisá-lo. O livro reconstitui minhas atribulações dentro e fora do ringue enquanto um aprendiz - incluindo minha luta no Chicago Golden Gloves - e mistura Sociologia, Etnografia e narrativa literária, texto e imagens, análise "fria" e experiência "quente", para levar o leitor ao quotidiano dos boxeadores comuns e recapitular em cores vívidas a produção específica de seu "complexo corpo-mente" (para usar uma expressão de William James que sugere uma afinidade entre o pragmatismo e a concepção da ação de Bourdieu).

Daí que o livro seja um estudo da produção social do habitus pugilístico como um conjunto de disposições particulares reunidas coletivamente por meio de uma pedagogia silenciosa que transforma a totalidade do ser do lutador ao extraí-lo do reino profano e introduzi-lo em um universo sensual, moral e prático distinto, trata-se de um processo de sedução a fim de refazer a si mesmo e adquirir honra (masculina) pela submissão voluntária às regras ascéticas de sua arte. $\mathrm{O}$ trabalho é uma radicalização empírica da teoria do habitus no qual se mostra de maneira quase experimental o quanto o habitus é um conjunto de desejos, vontades e habilidades, socialmente constituídas, que são ao mesmo tempo cognitivas, emotivas, estéticas e éticas, como ele é elaborado e como opera concretamente. Deixe-me citar uma passagem de Bourdieu que resume o que eu tentei 
demonstrar e indicar o que os boxeadores podem ensinar-nos sobre todos os agentes sociais: "Por meio de um jogo de palavras heideggeriano, poderse-ia dizer que a disposição é exposição. Justamente porque o corpo está (em graus diversos) exposto, posto em xeque, em perigo no mundo, confrontado ao risco da emoção, da ferida, do sofrimento, por vezes da morte, portanto obrigado a levar o mundo a sério (e nada é mais sério do que a emoção, que atinge o âmago dos dispositivos orgânicos), ele está apto a adquirir disposições que constituem elas mesmas aberturas ao mundo, isto é, às próprias estruturas do mundo social de que constituem a forma incorporada" (BOURDIEU, 1997a, p. 168).

Corpo e alma também toma seriamente em consideração a repreensão de Bourdieu de que as mais fundamentais e distintas competências que nós possuímos como seres sociais são conhecimentos e habilidades personificados, que operam sob o discurso e a consciência, em um sentido encarnado que surge de fora da mútua interpenetração do ser e do mundo. Se for verdade que nossa "presença-no-mundo" opera através do que ele chama de "o conhecimento pelo corpo" (essa é uma expressão mais apropriada que dá título a um capítulo de Meditações pascalianas idem, cap. 4; 2001e, cap. 4), então segue-se que para penetrar um dado universo como analistas sociais devemos obter conhecimento desse universo por meio de nossos corpos: devemos adquirir, e então investigar e problematizar, as categorias práticas, as sensibilidades e as habilidades que os nativos desenvolveram na e pela prática. Devemos elucidar a "illusio como essa maneira de estar no mundo" que emerge de ser de um certo mundo (idem, p. 162). Devemos, em suma, fazer não apenas a Sociologia $d o$ corpo - criaturas animais como construtos sociais - como também a Sociologia a partir do corpo - o organismo socializado e sensório como construtor social - que põe em primeiro plano a primazia cinética do mundo que faz membros reconhecidos de um dado universo o que e quem eles são.

Ainda em outro nível, Corpo e alma é uma aplicação da reflexividade como uma exigência de pesquisa e uma estratégia epistêmica, e demonstra pelo exemplo um dos argumentos centrais de $U m$ convite à sociologia reflexiva: que o propósito e a pedra de toque da boa teoria social é ajudar-nos a produzir novos objetos, detectar dimensões e dissecar mecanismos do mundo social que, de outra maneira, não estaríamos aptos para compreender. Há duas maneiras de concebermos e usarmos a teoria social: uma é o modo escolástico, no qual "dividimos, polimos e limpamos conceitos" - parafraseando C. Wright Mills (1958) em sua crítica a Talcott Parsons em $A$ imaginação sociológica - isto é, produzimos categorias teóricas como um fim em si mesmo, para exposição ritual e adoração. A outra é o modo gerativo, pelo qual desenvolvemos a teoria para usá-la em pesquisas empíricas e para provar e expandir sua capacidade heurística em um confronto sistemático com a realidade sócio-histórica. Eu espero que Corpo e alma ofereça um exemplo atraente da segunda concepção, embora isso também implique ser a teoria menos visível, e tenhamos então de extraí-la por meio de uma leitura atenta das observações que ela conduz (e nas quais ela às vezes se esconde).

- Nossa escolha da lógica da prática como tema deste número de $\mathrm{KX}$ Magazine dedicado a Bourdieu não apenas reconhece que ele fundou um novo tópico para pesquisas; também desejamos sublinhar os obstáculos ao seu desenvolvimento, o fato de que ela permanece, por enquanto, uma promessa não-cumprida. Você não concorda que, embora Bourdieu tenha proposto uma teoria da não-coincidência da teoria e da prática e mesmo afirmando explicitamente que o problema da lógica só pode ser compreendido na ação, encontrando "sua solução apenas em uma teoria da lógica teórica e da lógica prática" (BOURDIEU, 1980a, p. 155), ele parece relutante em desenvolver a teoria da lógica prática enquanto tal? Essa relutância não se deve ao fato de Bourdieu, tanto quanto imaginava ser possivel, pensá-la como uma álgebra (BOURDIEU, 1976, p. 73; 1980a, p. 435)?

Na minha opinião, o foco de Bourdieu na sua elaboração da lógica específica da prática e tudo que a distingue de uma "lógica da lógica" é comprovadamente sua grande descoberta e contribuição para a teoria social. Nós mal começamos a perceber sua importância e consumirá anos de trabalho em uma variedade de disciplinas - da Filosofia à Lingüística, da Estética à Sociologia para extrairmos todas as suas implicações (cf. WACQUANT, 1998b).

Agora, isso é um problema espinhoso, para o qual Bourdieu sugere duas soluções possíveis. $\mathrm{Na}$ 
versão "suave", ele propõe que existe um hiato entre a lógica imanente da prática, que é temporalmente inserida, espacialmente situada, ad hoc, indistinta, inconsciente de si mesma etc., e a lógica do conhecimento escolástico, que elimina a confusão e a ambigüidade embutidas por meio da ação "desencravadora" [disembedding action] e tirando dela algumas de suas qualidades distintivas enquanto ação. Mas esse hiato pode ser preenchido por um esforço consciente de teorização, por um retorno reflexivo sobre a análise da própria postura teórica, suas condições sociais de possibilidade, e como ela influencia a pesquisa como uma atividade prática (quais questões nós formulamos ou deixamos de formular, quais dados construímos, quais observações levamos a cabo etc.). Esse é o Bourdieu de Le sens pratique - por exemplo, quando ele explica a mudança decisiva da análise do parentesco de um conjunto de "regras" (como aparece no estruturalismo de LéviStrauss) para uma seqüência revelada de "estratégias" situadas, guiadas pela posição dos grupos no espaço social e pelo corpo como um "operador analógico" da prática (cf. BOURDIEU, 1980a; 1987; 1990c). Ou o Bourdieu de Dominação masculina (1997b; 1998a; 1999), que examina os trabalhos concretos dos mecanismos da violência simbólica que estão na origem da hegemonia masculina por meio de uma análise do ritual e da mitologia kabila e de como suas estruturas informam a vida cotidiana na sua - e em nossa sociedade.

$\mathrm{Na}$ versão "dura", que foi expressa cautelosamente pela primeira vez por Bourdieu (1990b; 1996e; 1998d) em "O ponto de vista escolástico", e que vem à tona novamente em certos trechos de Meditações pascalianas (embora esse trabalho seja ambíguo a esse respeito: ele também avança a "tese suave"...), há uma distância insuperável entre o conhecimento prático e o conhecimento científico, mesmo uma antinomia entre a prática como o impensado, o imediato e o mútuo "habitar" do ser e do mundo, complicação carnal com as forças ativas que fazem da existência social o que é, e o esforço para capturá-la por meio do pensamento, do raciocínio e da linguagem. O dilema não é tanto uma aporia quanto um impasse; o hiato não pode ser preenchido. Mas então, novamente, afirmar a tese "dura" não impede Bourdieu de levar adiante sua própria análise das condições sociais que leva em conta a "ambigüidade fundamental da disposição escolástica”, nomeadamente, que ela capacita-nos a conhecer o mundo enquanto o mutila, na medida em que requer que nos retiremos do mundo e nos inclinemos para vê-lo como algo diferente do que é por ele mesmo - como um espetáculo suscetível de ser lido à maneira de um texto (como com a "descrição densa" de Clifford Geertz), ou com os trabalhos autotélicos de uma álgebra semiótica (como em Lévi-Strauss e no assim chamado pós-estruturalismo, que na verdade é estruturalismo mas com outro nome) - mais que tarefas urgentes a serem realizadas praticamente hic et nunc.

Eu penso que a tensão não está resolvida, e que a questão é se ela provar-se-á frutífera, isto é, se conduz à heurística progressiva, no sentido que Lakatos dá ao termo. Isso é o que, com ironia pascaliana, poderíamos batizar de "a aposta de Bourdieu": mesmo que possa haver uma contradição insuperável entre a lógica da prática e a lógica da ciência como uma forma historicamente datada e situada de prática humana, nós estamos em melhor situação agindo como se não houvesse e seguindo em frente no projeto de uma ciência da sociedade. A prova do pudim teórico da prática será encontrada no comer prático.

\section{UMA OFICINA SOCIOLÓGICA EM AÇÃO: ACTES DE LA RECHERCHE}

Lançada em 1975 com a benção e o apoio de Fernand Braudel, o diretor da Maison des Sciences de l'Homme, onde parmaneceu baseada por vinte anos, a revista Actes de la recherche en sciences sociales firmou-se como uma das mais importantes publicações em Ciências Sociais no mundo, embora tenha permanecido altamente singular em seu formato, tom e missão. Ela municiou o desenvolvimento de uma perspectiva sociológica característica, inspirada pela visão cívica e científica de Pierre Bourdieu, que tanto continuou quanto rompeu com a longa linhagem da Escola Sociológica Francesa. Actes de la recherche encorajou a internacionalização da ciência social em um meio parisiense cuja predileção pela autarquia intelectual é incomparável. Além disso, a revista procura publicar os mais avançados produtos da pesquisa social a fim de impingi-los sobre a consciência coletiva e sobre a discussão pública na França e no exterior.

Actes de la recherche mantém a inconfundível marca de seu fundador e editor-chefe, o sociólogo Pierre Bourdieu, cuja infatigável orientação impulsionou a revista por mais de três décadas e 
cuja prodigiosa produção científica conformou profundamente seus conteúdos. Mas ela é o resultado da atividade conjunta de uma ampla rede de acadêmicos ancorada no Centre de Sociologie Européene do Collège de France e de seus associados e filiados estrangeiros, como se pode ver pelas diversas origens, estilos e inclinações teóricas de seus colaboradores.

Diferentemente de Esprit ou Les Temps Modernes, Actes de la recherche é mais uma revista cientifica que intelectual, de maneira que a validade metodológica e a adequação empírica têm prioridade sobre a elegância literária e a retidão política. Em contraste com L'Homme ou Annales: économies, sociétés, civilisations, entretanto, ela é obstinadamente transdisciplinar e atenta aos temas sociopolíticos da atualidade: é o órgão de uma ciência da sociedade militante cujo público é basicamente, embora não exclusivamente, composto por intelectuais. Ainda, ao contrário de $L e$ débat, sua ambição não é ecoar, mas questionar a moda intelectual e política, baseada na noção de que uma ciência social autocrítica pode e deve funcionar como um "serviço público", desafiando implacavelmente as idéias instituídas e os modos de pensar estabelecidos. De fato, assim como o Année sociologique serviu como ponto focal das trocas acadêmicas e veículo do republicanismo sublimado da escola durkheimiana no início do século XX, a Actes de la recherche foi elaborada como uma plataforma para a Sociologia transdisciplinar, casando o rigor científico, a reflexividade metodológica e a relevância sócio-política.

O longo e de fato desajeitado título-Actes de la recherche en sciences sociales - almeja expor tanto os objetos sociológicos quanto os "métodos de pesquisa" necessários para trazê-los à luz, ou melhor, para construi-los como tais. Pois o ponto de partida epistemológico implícito da revista (originado na filosofia do conceito de Gaston Bachelard e Georges Canguilhem) estipula que os fatos sociais não surgem prontos na realidade: eles precisam ser conquistados das percepções ordinárias e do senso comum acadêmico. Rejeitando a estilização dos relatórios de pesquisa das Ciências Sociais, que tendem a esconder o "trabalho sujo" levado a cabo na cozinha sociológica, Actes de la recherche "deve não apenas demonstrar mas também mostrar". Pois o objetivo específico deste laboratório-em-ação sociológico é precisamente "desmascarar as formas sociais e os formalismos" pelos quais a realidade dissimula a si mesma (trecho do editorial sem título, introdutório ao número inaugural). Daí sua submissão a temas "transversais", recortados de maneiras contra-intuitivas que viram do avesso concepções aceitas e elevam os objetos "inferiores" enquanto rebaixam os "superiores" (não é por mera coincidência que o primeiro artigo do primeiro número discutia "O método científico e a hierarquia social de objetos").

Para obter rigor e relevância sem subserviência a preceitos doutrinários e para tornar a Sociologia viva para seus leitores, Actes de la recherche multiplicou as experiências formais e as inovações estilísticas. Em primeiro lugar, publicaram-se não apenas artigos acadêmicos padrão como também resenhas curtas, peças polêmicas, notas de leitura, documentos inéditos e relatórios de campo ou experimentais rigorosamente editados, autoreflexivos (ver, por exemplo, "Anotações para uma sócio-análise", de Yvette Delsaut, e "Uma noite em uma galeria de tiro", de Philippe Bourgois, respectivamente nos números de fevereiro de 1986 e setembro de 1992 (BOURGOIS, 1992)). Em segundo lugar, o artigo arquetípico dos Actes tece o texto com fotografias, fac-símiles de exposições e excertos de entrevistas ou dados crus de observações em caixas e barras laterais dispostas ao longo do texto. A revista utiliza também diferentes tipos e fontes e mistura estilos diretos e indiretos, tudo em um esforço para unir a precisão analítica com a acuidade experimental.

A revista tem procurado constantemente desnacionalizar a pesquisa social por meio da abertura de uma ampla janela às escolas estrangeiras, ligando os desenvolvimentos das investigações sócio-culturais francesas às tendências e avanços no exterior e vice-versa. Próximo aos Annales, ela é o periódico de Ciências Sociais baseado em Paris cuja orientação internacional é mais significativa. De fato, a lista de autores nãofranceses publicados na Actes de la recherche é um verdadeiro "quem é quem" do mundo das Ciências Sociais: Michael Baxandal e Howard Becker, Michael Burawoy e Aaron Cicourel, Nils Christie e Robert Darnton, Norbert Elias e Carlo Ginsburg, Johann Goudsblom e Eric Hobsbawm, Jürgen Kocka e William Labov, Wolf Lepenies e Eleanor Maccoby, Nancy Scheper-Hughes e Gerschom Sholem, Joan Scott e Carl Schorske, Armatya Sen e Theda Skocpol, Ivan Szelenyi e Jeno Szücs, Raymond Williams, Paul Willis e Viviana Zelizer. Muitos renomados autores 
franceses também foram publicados pela revista antes de obterem aclamação internacional: a lista vai de Maurice Agulhon e Jacques Bouveresse a Robert Linhart e Bruno Latour. E mais: durante esses anos Actes de la recherche procurou descobrir e difundir o trabalho de jovens acadêmicos, juntamente com textos pouco conhecidos de autores clássicos (E. C. Hughes, Mauss, Goffmann, Weber e Wittgenstein). Ao lado de autores estrangeiros e jovens pesquisadores, Actes de la recherche também publica mais artigos de mulheres que a maioria, senão todas, as revistas de Ciências Sociais de estatura e alcance semelhante.

Sem ceder nada aos modismos políticos e aos assuntos novidadeiros, a revista empenha-se em manter um pé na sociedade e em contribuir para a continuidade dos debates sócio-políticos de uma perspectiva rigorosamente científica. Portanto, ela persegue a missão cívica da ciência social: a busca da autonomia científica e o retorno do conhecimento, produzido por essa autonomia, à esfera pública (BOURDIEU, 1989b). Por exemplo: no outono de 1980, quando os tanques soviéticos rumavam para Cabul, Actes de la recherche lançou um artigo intitulado: "Et si on parlait de l'Afghanistan?" (CENTLIVRES \& MICHELINE, 1980). Em 1988, às vésperas da disputa presidencial entre Mitterrand e Chirac, uma série de artigos de expoentes da Ciência Política, da Sociologia e do Direito procurou "Repensar a política". No início dos anos 1990, novas formas de desigualdade social e marginalidade surgiram, eludindo os instrumentos tradicionais de protesto coletivo. Em resposta, Actes de la recherche publicou uma série de estudos baseados em biografias retratando as origens sociais e as implicações desses "sofrimentos sociais" (esses estudos foram depois expandidos em um sucesso de vendas, de cerca de mil páginas, uma sócioanálise da França contemporânea publicada como A miséria do mundo-BOURDIEU, 1993a; 1997f). Acompanhando de perto as maciças manifestações de rua ocorridas em dezembro de 1995 contra a insegurança social, o número de novembro de 1996 de Actes, sobre "As novas formas de dominação no trabalho", trouxe aos seus leitores uma análise organizacional da sobrecarga do trabalho nos transportes rodoviários justamente quando os motoristas de caminhão estavam paralisando o país com bloqueios de estrada. Em 1997, quando o debate sobre a "globalização" e suas patologias cresceu, a revista reuniu um conjunto de pesquisas aprofundadas, de âmbito internacional, sobre "Os economistas e a economia" (Actes de la recherche, 1997) ${ }^{6}$.

Em outro sentido, Actes de la recherche en sciences sociales pode ser caracterizada por seus objetos privilegiados e temas recorrentes. $\mathrm{O}$ principal deles é a economia dos bens culturais. Literatura e imaginário popular, pintura e livros, música e museus, moda e gosto, religião e academia, mito e ciência (bem como suas interseções: mitos, crenças e ritos científicos): a produção, a circulação e o consumo desses bens obedece a leis peculiares que são melhor revelados pela analogia e pela análise comparativa em uma série de questões. Um outro assunto preferencial é a lógica da classificação social e a fabricação de coletivos sociais. Estudos sobre a constituição (ou o desfazimento) da classe, do gênero, da etnicidade, da idade, da região, da nação e do império convergem para mostrar como princípios alternativos de visão e divisão sociais constituem ferramentas e marcos nas lutas simbólicas, pelas quais a realidade social é de uma vez dotada de facticidade e revelada como um edifício precário. Essa preocupação com a desconstrução de entidades sociais "naturalizadas" [ready-made] estende-se também a "recipientes" familiares da vida social, tais como a família, a empresa, o partido e o Estado. A preocupação correlata em documentar a necessidade social trabalhando por detrás de realidades sociais extremas abrange instituições aparentemente exóticas, como a música popular, o futebol, os campos de concentração e o gueto afro-americano.

Um terceiro núcleo temático centra-se nas estratégias sociais de dominação, distinção e reprodução: entre elas figuram estudos de grupos domiciliares, escolas e consumo, trabalho e labor, as bases e os efeitos das políticas públicas, a interseção da economia e da moral, e o papel da prática política e das leis. Last but not least, Actes de la recherche esquadrinha continuamente as práticas, as complicações e os poderes intelectuais. Assim, números sobre "As categorias do entendimento profissional" (setembro de 1975), "A ciências e a atualidade" (fevereiro de 1986), "Pesquisa sobre a pesquisa" (setembro de 1988), "A história social

\footnotetext{
6 Cf. os artigos de Bourdieu (1997), Fligstein (1997),
} Lebaron (1997) e Lordon (1997) (N. Ed.). 
das ciências sociais" (junho e setembro de 1995) e "As astúcias da razão imperialista" (fevereiro de 1998) atestam a necessidade de pôr os acadêmicos sob seu próprio microscópio a fim de desvelar e, espera-se, melhor controlar - os determinantes sociais do pensamento social. Entre os artigos clássicos sobre a sociologia dos intelectuais, podemos indicar: "A ontologia política de Martin Heidegger", de Pierre Bourdieu (BOURDIEU \& BOLTANSKI, 1975); "Paul Lazarsfeld, fundador de uma multinacional científica", de Michael Pollak (1995); "Louis Dumont e a ciência nativa", de Roland Lardinois (1995); a dissecação da trajetória literária de François Mauriac, por Gisèle Sapiro (1996), e as peças incisivas sobre os "intelectuais parodistas" do Tel Quel e dos grupos parisienses relacionados, da autoria de Louis Pinto (1998).

Em suma: o impulso diretor por trás das variadas investigações publicadas em Actes de la recherche vai no sentido de desnaturalizar as categorias, os fatos e as instituições sociais, ao mesmo tempo em que provê os meios para recapitular e aceder as diferentes etapas da demonstração que estão à mão. Essa fórmula provou ter apelo: com um público leitor regular próximo a dez mil, Actes satisfaz um amplo público que se estende para bem além da academia - há apenas cerca de mil sociólogos na França. Os demais leitores incluem não somente pesquisadores como também professores e estudantes universitários, assistentes sociais, ativistas e empresários culturais, bem como outros estratos instruídos com interesse em pesquisas e questões sociais (alguns números tiveram vendagens superiores a vinte mil exemplares). Com "revistas irmãs" na
Espanha, no Japão e no Brasil, que reimprimem artigos-chave traduzidos, seu público internacional vai muito além do âmbito francófono. Desde 1989, Actes é ladeada por um suplemento, Liber: revue internationale des livres, publicado simultaneamente em nove países e línguas europeus, cujo objetivo é avançar burlando as estruturas nacionais e acelerar a circulação continental de trabalhos inovadores e comprometidos nas Artes, nas Humanidades e nas Ciências Sociais.

Actes de la recherche en sciences sociales permanece uma operação largamente artesanal, com uma pequena equipe e limitado apoio institucional, quase desproporcional ao seu impacto nacional e adeptos internacionais. O sucesso tende inevitavelmente a diluir a fórmula original que o produziu; como o grupo tanto de autores quanto de leitores expande-se, o espírito científico e cívico específico da revista torna-se mais difícil de manter. Pode-se esperar de Actes de la recherche que evolua em resposta às mudanças das correntes $\mathrm{e}$ constrangimentos intelectuais enquanto permanece fiel à sua vocação inicial: promover aquela ciência social rigorosa e transdisciplinar de todo o planeta que funde a pesquisa e a teoria, ao mesmo tempo em que permanece alerta às implicações políticas e éticas da investigação social. Ao fazê-lo, ela renova a militância científica e o internacionalismo da Escola Sociológica Francesa. Assim como com Durkheim e o Année sociologique, seu maior desafio é sobreviver ao passamento final da geração acadêmica que a criou e dela cuidou. Ler Actes de la recherche en sciences sociales nos próximos anos promete ser então um intrigante experimento sobre a rotinização do carisma intelectual.

Loiq Wacquant (loic@uclink4.berkeley.edu) é Professor de Sociologia na Universidade da Califórnia (Berkeley) e é Pesquisador do Centre de sociologie européenne do Collège de France. É autor, com Pierre Bourdieu, de Um convite à sociologia reflexiva (1992).

\section{REFERÊNCIAS BIBLIOGRÁFICAS}

BOURDIEU, P. 1972. Esquisse d'une théorie de la pratique. Paris : Points.

1974. A economia das trocas simbólicas. São Paulo : Perspectiva.

1976. Le sens pratique. Actes de la recherche en sciences sociales, Paris, n. 1, p. 4386 , fév.
1977. Algérie 60. Strutures économiques et structures temporelles. Paris : Minuit.

. 1979a. La distinction : critique sociale du jugement. Paris : Minuit.

.1979b. O desencantamento do mundo : estruturas econômicas e estruturas sociais. São Paulo : Perspectiva. 
. 1980a. Le sens pratique. Paris : Minuit.

. 1980b. Questions de Sociologie. s/1 : s/n.

. 1981. Questões de Sociologia. Rio de Janeiro : Marco Zero.

. 1982. Leçon sur la leçon. Paris : Minuit.

. 1984a. Homo academicus. Paris : Minuit.

. 1984b. Langage et pouvoir symbolique.

Paris : Points.

1987. Choses dites. Paris : Minuit.

. 1988a. L'Ontologie politique de Martin Heidegger. Paris : Minuit.

. 1988b. Lições da aula. São Paulo : Ática.

. 1989a. La Noblesse d'Etat : grandes écoles et esprit de corps. Paris : Minuit.

. 1989b. The Corporatism of the Universal : The Role of Intellectuals in the Modern World. Telos, n. 81, p. 99-110, Fall.

. 1989c. O poder simbólico. Rio de Janeiro : Bertrand Brasil.

. 1989d. A ontologia política de Martin Heidegger. Campinas : Papirus.

. 1990a. The Logic of Practice. Cambridge : Polity Press.

. 1990b. The Scholastic Point of View. Cultural Anthropology, n. 5-4, p. 380-391, Nov.

. 1990c. Coisas ditas. São Paulo : Brasiliense.

. 1992. Les Règles de l'art: genèse et structure du champ littéraire. Paris : Seuil.

. (org.). 1993a. La misère du monde. Paris : Seuil.

.1993b. In Other Words : Essays towards a Reflexive Sociology. Cambridge : Polity Press.

.1993c. Lecture on the Lecture. In :

In Other Words : Essays towards a Reflexive Sociology. Cambridge : Polity Press.

.1994. Raisons pratiques. Sur la théorie de l'action. Paris : Editions du Seuil

. 1995. Livre troca: diálogos entre ciência e arte. Rio de Janeiro : Bertrand Brasil. d'agir. .1996b. A economia das trocas lingüisticas : o que falar quer dizer. São Paulo : Edusp.

1996c. As regras da arte : gênese e estrutura do campo literário. São Paulo : Companhia das Letras.

.1996d. Razões práticas : sobre a teoria da ação. Campinas : Papirus.

. 1996e. O ponto de vista escolástico. In : . Razões práticas : sobre a teoria da ação. Campinas : Papirus.

1997a. Méditations pascaliennes : éléments pour une philosophie négative. Paris : Seuil.

. 1997b. Masculine Domination Revisited : The Goffman Prize Lecture. Berkeley Journal of Sociology, Berkeley, n. 41, p. 189-203.

. 1997c. Le champ économique. Actes de la recherche en sciences sociales, Paris, n. 119, p. 48-66, sept.

. 1997d. Liber I. São Paulo : Edusp.

.1997e. Sobre a televisão. Rio de Janeiro : Jorge Zahar.

. (org.). 1997f. A miséria do mundo. Vozes : Petrópolis.

1998a. La Domination masculine. Paris : Editions du Seuil.

1998b. Contre-feux 1 : propos pour servir à la résistance contre l'invasion néo-libérale. Paris : Raisons d'agir.

. (org.). 1998c. The Poverty of Society : A Study in Social Suffering. Cambridge : Polity Press.

.1998d. Practical Reasons. Cambridge : Polity Press.

. 1998e. Contrafogos 1 : táticas para enfrentar a invasão neoliberal. Rio de Janeiro : Jorge Zahar.

. 1999. A dominação masculina. Rio de Janeiro : Bertrand Brasil.

.2000. O campo econômico : a dimensão simbólica da dominação. Campinas : Papirus.

.2001a [1957]. Sociologie d'Algérie. Paris : Presses Universitaires de France.

2001b. Contre-feux 2 : pour un movement 
social eurepéen. Raisons d'agir.

.2001c. Science de la science et réflexivité.

Paris : Raisons d'agir.

.2001d. Controfogos 2 : por um movimento social europeu. Rio de Janeiro : Jorge Zahar.

.2001e. Meditações pascalianas. Rio de Janeiro : Bertrand Brasil.

. 2002a. Interventions. 1961-2001. Marseilles : Agone.

. 2002b. Le Bal des célibataires. La crise de la société paysanne en Béarn. Paris : Seuil/ Points.

.2002c. A produção da crença : contribuição para uma economia dos bens simbólicos. São Paulo : Zouk.

BOURDIEU, P. \& BOLTANSKI, L. 1965. Un art moyen : essai sur les usages sociaux de la photographie. Paris : Minuit.

1975. L'ontologie politique de Martin Heidegger. Actes de la recherche en sciences sociales, Paris, n. 5-6, p. 109-156.

BOURDIEU, P. \& DARBEL, A. 1966. L'amour de l'art : les musées d'art européens et leur public. Paris : Minuit.

BOURDIEU, P. \& HAACKE, H. 1994. Libreéchange. Paris : Seuil.

BOURDIEU, P. \& PASSERON, J.-C. 1964. Les héritiers : les étudiants et la culture. Paris : Minuit.

1970. La reproduction : éléments d'une théorie du système d'enseignement. Paris : Minuit.

1975 [1970]. A reprodução : elementos para uma teoria do sistema de ensino. Rio de Janeiro : Francisco Alves.

BOURDIEU, P. \& SAYAD, A. 1964. Le déracinement. La crise de l'agriculture traditionnelle en Algérie. Paris : Minuit.

BOURDIEU, P. \& WACQUANT, L. 1992. An Invitation to Reflexive Sociology. Chicago: The University of Chicago Press.

BOURDIEU, P., CHAMBOREDON, J.-C. \& PASSERON, J.-C. 1990 [1968]. The Craft of Sociology: Epistemological Foundations. New York : Aldine de Gruyter.
1999 [1993]. The Weight of the World: Social Suffering in Contemporary Society. Cambridge : Polity Press. 2000. A profissão de sociólogo : preliminares epistemológicas. Petrópolis : Vozes.

BOURDIEU, P., DARBEL, A., RIVET, J.-P. \& SEIBEL, C. 1963. Travail et travailleurs en Algérie. Paris : Mouton.

BOURGOIS, P. 1992. Une nuit dans une shooting gallery. Enquête sur le commerce de la drogue à East Harlem. Actes de la recherche en sciences sociales, Paris, n. 93, p. 59-78, sept.

CENTLIVRES, P. \& MICHELINE. 1980. Et si on parlait de l'Afghanistan? Entretien avec Pierre Bourdieu. Actes de la recherche en sciences sociales, Paris, n. 34, p.2-16.

FLIGSTEIN, N. 1997. Rhétorique et réalités de la «mondialisation». Actes de la recherche en sciences sociales, Paris, n. 119, p. 36-47, sept.

LEBARON, F. 1997. La dénégation du pouvoir. Le champ des économistes français au milieu des années 1990. Actes de la recherche en sciences sociales, Paris, n. 119, p. 3-26, sept.

LORDON, F. 1997. Le désir de "faire science». Actes de la recherche en sciences sociales, Paris, n. 119, p. 27-35, sept.

MILLS, C. W. 1958. The Sociological Imagination. New York : Oxford University Press.

PINTO, L. 1998. Épreuves et prouesses de l'esprit littéraire. Actes de la recherche en sciences sociales, Paris, n. 123, p. 45-64.

POLLAK, M. 1979. Paul F. Lazarsfeld, fondateur d'une multinationale scientifique. Actes de la recherche en sciences sociales, Paris, n. 25, p. 45-59.

POUPEAU, F. \& DISCEPOLO, T. (eds.). 2002. Bourdieu : interventions politiques 1964-2000. Paris : Agone.

ROLAND, L. 1995. Louis Dumont et la science indigène. Actes de la recherche en sciences sociales, Paris, n. 106-107, p. 11-26.

SAPIRO, G. 1996. La raison littéraire. Le champ littéraire français sous l'Occupation (19401944). Actes de la recherche en sciences sociales, Paris, n. 111-112, p. 3-35.

WACQUANT, L. 1998a. A Sociological 
Workshop in Action: Actes de la recherche en sciences sociales. In: KRITZMAN, L. D. (ed.). The Columbia History of Twentieth-Century French Thought. New York : Columbia University Press.

. 1998b. The Double-Edged Sword of Reason : The Scholar's Predicament and the Sociologist's Mission. European Journal of Social Theory, London, n. 2-3, p. 275-281, Spring.
2000. Corps et âme. Carnets ethnographiques d'un apprenti boxeur. Marseille : Agone, Comeau et Nadeau.

. 2002a. Corpo e alma. Notas etnográficas de um aprendiz de boxe. Rio de Janeiro : Relume-Dumará.

2002b. The Sociological Life of Pierre Bourdieu. International Sociology, London, v. 17, n. 4, p. 549-556, Dec.

\section{OUTRAS FONTES}

Actes de la recherche en sciences sociales. 1975.

Paris, n. 3, sept.

. 1986. Paris, n. 61, fév.

. 1988a. Paris, n. 71-72, fév.

. 1988b. Paris, n. 74, sept.

. 1990. Paris, n. 100, déc. Édition special d'anniversaire. . 1995. Paris, n. 108, juin-sept. . 1996. Paris, n. 115, nov. . 1997. Paris, n. 119, sept. . 1998. Paris, n. 121-122, fév. 
investment that has been made in the automobile industry in the Greater Curitiba, state of Paraná. The research adopts a perspective on globalization that takes into account both global structures and mechanisms as well as the decision-making sphere of local government. The authors come to the conclusion that researchers should include social as well as political aspects in their analyses, as well as research the investments, strategies and operations of transnational firms in Brazil, employing interdisciplinary approaches that take international economic policy into account.

KEYWORDS: globalization, transnational enterprise, automobile industry.

$* * *$

\section{LABOR AND UNIONISM IN BRAZIL: A CRITICAL INVENTORY OF THE "NEOLIBERAL DECADE" (1990-2000)}

Giovanni Alves (Universidade Estadual Paulista - Marília)

This article presents an overview of principal shapes that the world of labor took on in Brazil during the nineties. We refer to this period as the "neo-liberal decade". We emphasize the development of a new complex of productive restructuring and its dominant moment (Toyotism), as well as the emergence of a new (and precarious) world of labor and the advent of the crisis of unionism, which we consider to be the contingent expression of the fragmentation of the working class. We come to the conclusion that today more than ever, at the start of the twenty first century, the greatest challenge that Brazilian unionism faces involves a break with its bureaucratic-corporative bias, as well as the organization and mobilization of a massive contingent of young workers and employees and even the precarious self-employed or workers subject to capitalist exploitation. We make critical use of empirical data from books and essays written by researchers from the fields of economics, sociology of work and industrial sociology in Brazil over the last decade

KEYWORDS: labor; unionism; Neo-liberalism; Toyotism, unemployment.

$* * *$

PIERRE BOURDIEU'S SOCIOLOGICAL LEGACY: TWO DIMENSIONS AND A PERSONAL NOTE

Loïc J. D. Wacquant (University of California, Berkeley/Centre de sociologie européene du Collège de France)

This article is made up of three parts, each of which re-traces and discusses the life and sociological work of Pierre Bourdieu, who died in January of 2002. The first section discusses the French thinker's career, and seeks to relate each stage of his life with the ongoing development of his thought - from his primary schooling in the French interior to his international recognition, and including his studies in Philosophy in Paris and anthropological research in Algeria. The second section uses an interview to engage in a discussion of reflexive sociology, of "the logic of practice", and of other concepts that Bourdieu formulated for the study of social reality and to incite the discovery of new research agendas. The third section discusses the importance of the journal Actes de la recherche en sciences sociales which Bourdieu founded, meant to transcend the several boundaries of nationality and disciplines which circumscribe and limit scientific production.

KEYWORDS: Pierre Bourdieu; intellectual trajectory; reflexive sociology; the logics of practice; Actes de la recherche en sciences sociales.

$* \quad * *$

EXPLAINING THE MANAGEMENT STATE'S IMPLEMENTATION CRISIS: PERFORMANCE VERSUS FISCAL ADJUSTMENT

Flávio da Cunha Rezende (Universidade Federal de Pernambuco) 
Cet article présente les résultats préliminaires d'une recherche dont l'objectif est de développer une référence théorique afin d'analyser les antécédents et les implications de la globalisation économique au Brésil. Plus particulièrement, l'article met en relief les problèmes de gouvernement et maintien environnemental concernant les investissements directs étrangers qui ont été effectués dans l'industrie automobile de la région de Curitiba, dans l'état du Paraná. La recherche suit une perspective particulière de globalisation qui considère autant les mécanismes et structures globales que l'espace de décision des gouvernements locaux. Les auteurs considèrent finalement que les chercheurs doivent prendre en compte non seulement les aspects sociaux mais encore les aspects politiques dans leurs analyses et qu'il faut entreprendre, lorsqu'on mène des recherches portant sur investissements, stratégies et opérations des entreprises transnationales, des approches interdisciplinaires compte tenu de l'approche du domaine de l'économie politique internationale.

MOTS-CLÉS: globalisation; entreprise transnationale; industrie automobile.

\section{TRAVAIL ET SYNDICALISME AU BRESIL: UN BILAN CRITIQUE “DES ANNÉES NEO- LIBERALES" (1990-2000)}

Giovanni Alves (Universidade Estadual Paulista - Marília)

Cet article présente un tableau des principaux contours du monde du travail au Brésil, dans les années 90. On appelle cette période "les années néo-libérales". On souligne le développement d'un nouveau réseau de restructuration productive et son moment le plus important (le toyotisme), la naissance d'un nouveau (et fragile) monde du travail et l'avènement de la crise du syndicalisme, considérée comme l'expression nécessaire de la fragmentation de la classe ouvrière. On estime qu'aujourd'hui, plus que jamais, le grand défi du syndicalisme au Brésil à l'aube du XXI ${ }^{\text {ème }}$ siècle est de rompre avec la tendance burocratique-corporatiste, d'organiser et de mobiliser un contigent important de jeunes ouvriers et ouvrières, employés, y compris les travailleurs indépendants en situation difficile et exploités par le capital. On a utilisé, dans une perspective critique, les données empiriques des livres et des essais de chercheurs du domaine de l'économie et de la sociologie de l'industrie et du travail au Brésil, parus tout au long des années 90.

MOTS-CLÉS: travail; syndicalisme; néo-libéralisme; toyotisme; chômage.

\section{L'HERITAGE SOCIOLOGIQUE DE PIERRE BOURDIEU: DEUX DIMENSIONS ET UNE TOUCHE PERSONNELLE}

Loïc J. D. Wacquant (University of Californie, Berkeley/Centre de socilogie europénne du Collège de France)

Cet article est composé de trois parties où l'on retrace la vie et l'oeuvre sociologique de Pierre Bourdieu, décédé en janvier 2002 et l'on en discute. La première partie présente la carrière du penseur français et cherche à mettre en rapport chaque étape de sa vie avec le développement de sa pensée depuis les premières études en province jusqu'à sa renommée internationale. On se reporte également à ses études de philosophie à Paris et aux investigations anthropologiques en Argélie. La seconde partie consiste en un débat, par le biais d'une interview, de la sociologie réflexive, de la "logique de la pratique" et d'autres concepts formulés par Bourdieu avec l'objectif d'étudier la réalité sociale et d'inciter à la découverte des nouveaux agendas de recherche. La troisième partie a pour thème l'importance de la revue Actes de la recherche en sciences sociales, fondée par le sociologue et destinée à dépasser les diverses frontières de nationalité et de disciplines, qui entourent et limitent la production scientifique.

MOTS-CLES: Pierre Bourdieu; trajectoire intellectuelle; sociologie réflexive; logique de la pratique; 
Actes de la recherche en sciences sociales.

\section{LES RAISONS DE LA CRISE D'IMPLEMENTATION DE L'ETAT GESTION: PERFORMANCE ET AJUSTEMENT FISCAL}

Flávio da Cunha Rezende (Universidade Federal de Pernambuco)

Cet article se compose de trois buts différents: d'abord, il présente la crise d'implémentation des politiques de réforme administrative et en discute. Ensuite, il fait la révision des principales théories contemporaines abordant le sujet. Enfin, il suggère une théorie aditive qui met en rapport la crise d'implémentation des réformes et le problème des limites pour l'obtention de la collaboration simultanée en fonction des objectifs du programme d'ajustement fiscal et changement institutionnel. La théorie proposée prône que la tension entre plus de flexibilité burocratique, d'une part, et la demande d'une plus grande rigueur dans les systèmes internes de contrôle burocratiques, d'autre part, est un puissant mécanisme causal qui tend à générer des crises successives d'implémentation de ces propositions politiques. Aussi les réformes tendent-elles à générer une résistance organisée au changement, des problèmes de coordination, des problèmes d'action collective et d'autres problèmes. L'article argumente que, bien que cette explication soit valable d'une façon générale pour le cas des réformes administratives, il se peut que ce soit plus compliqué pour les réformes de gestion où la contradiction entre les objectifs d'ajustement fiscal et le changement intitutionnel est plus intense.

MOTS-CLÉS: réformes administratives; politiques publiques; implémentation des politiques publiques.

COMPORTEMENT ELECTORAL VOLAGE ET REELECTION: LES VICTOIRES DE JAIME LERNER DANS L'ETAT DU PARANÁ

Emerson Urizzi Cervi (Faculdade Internacional de Curitiba)

Cet article présente, données socioéconomiques de la région et résultats des élections pour le gouverneur de l'État du Paraná en 1994 et 1998 à l'appui, des éléments indicant une très grande volatilité électorale qu'on ne peut saisir dans une analyse de l'agregé de l'état. J'analyse les résultats électoraux du vote pour l'exécutif du Paraná à partir d'une coupe géographique, définissant les villes comme unités d'analyse. Les voix obtenues par les candidats dans les villes de l'état sont regroupées selon la dimension des unités et d'après leur développement socioéconomique, vérifié par l'IDH-V (Indicateur de développement humain de la ville en 1991). Les villes sont partagées en micro, petites, moyennes et grandes. Pour établir une référence de développement économique et social, j'utilise l' Indicateur de développement humain (IDH), classant les villes en IDH très bas, IDH bas, IDH moyen et IDH élevé. L'objectif du travail est d'identifier géographiquement et socialement les électeurs des principaux candidats au gouvernement du Paraná dans les deux élections analysées. Ensuite, je démontre l'existence d'une volatilité électorale importante dans les deux élections remportées par Jaime Lerner ce qui n'est pas saisi lorsqu'on analyse le résultat agrégé des voix. L'article discute notamment du comportement électoral dans les démocraties populaires où l'électeur est considéré comme l'agent du processus électoral dont les inclinations et demandes changent en permanence.

MOTS-CLÉS: comportement électoral; démocratie populaire; volatilité électorale; gouvernement du Paraná; Jaime Lerner. 